\title{
Prevention of severe hypoglycaemia in type I diabetes: a randomised controlled population study
}

\author{
S Nordfeldt, C Johansson, E Carlsson, J-Å Hammersiö
}

See end of article for authors' affiliations

.....................

Correspondence to: Dr S Nordfeldt, Dept of Molecular and Clinical Medicine, Division of Pediatrics, Faculty of Health Sciences, S-581 85 Linköping, Sweden; sam.nordfeldt@lio.se

Accepted 14 October 2002

\begin{abstract}
Aims: To investigate use of targeted self study material in type I diabetes patient education regarding dissemination, perceived patient benefit, and prevention of severe hypoglycaemia.

Methods: In a randomised 1:1:1 controlled study, 332 patients with type I diabetes (aged 2.6-18.9 years) were studied; 313 completed clinical follow up, 261 completed endpoint questionnaire. The intervention group received videotapes and a brochure designed to review skills for self control and treatment, aimed at preventing severe hypoglycaemia. Two control groups received a videotape and brochure with general diabetes information, or traditional treatment only, respectively.

Results: Yearly incidence of severe hypoglycaemia decreased from $42 \%$ to $27 \%$ in the intervention group, but not in controls. HbAlc remained unchanged. Levels of use ranged from 1 to 20 times (median 2); 40-49\% had shown the materials to friends, relatives, school staff, sports coaches, etc (there was little difference between intervention and control groups). Higher benefit and learning levels resulted from the intervention material, especially in patients with severe hypoglycaemia.

Conclusions: Mass distributed pedagogical devices such as high quality video programmes and brochures may contribute to the prevention of severe hypoglycaemia. Such self study materials can reach high dissemination levels and constitute a cost effective complement to regular visits to a diabetes team and to other types of education. The findings may have implications for other topics, other ages, and other diagnosis groups.
\end{abstract}

with he importance of modern multiple dose insulin therapy with near physiological glycosylated haemoglobin levels to prevent, delay, or slow the progression of long term complications of type I diabetes has been apparent since the 1980s. ${ }^{1}$ However, severe hypoglycaemia has been the major acute complication ever since 1922, when the life saving insulin treatment was first given to a boy in Canada. ${ }^{23}$ In the twenty first century severe hypoglycaemia is still a serious problem in the lives of many children and adolescents, even though they receive the most modern treatments for their diabetes. ${ }^{45}$ On average, $40 \%$ of children need help with severe hypoglycaemia episodes, with or without loss of consciousness, at least once a year. ${ }^{67}$ Studies of continuous glucose monitoring indicate that much more hypoglycaemia occurs than is detected with blood glucose determinations. ${ }^{8}$

The multifactorial aetiology of severe hypoglycaemia is only partially known. ${ }^{3}$ Determinants related to biology and treatment, such as glycosylated haemoglobin, diabetes duration, and insulin dose, may explain only a small proportion of the variation. ${ }^{4}$ However, an earlier history of severe hypoglycaemia is another predictor for such events, ${ }^{9}$ and we recently suggested a genetic determinant (in press). Furthermore, it has been reported that a marker of lower socioeconomic status may predict severe hypoglycaemia. ${ }^{10}$ Self care behaviours and patient education may also be of importance. ${ }^{11-13}$ Moreover, reported incidences of severe hypoglycaemia vary even between clinics in the same multicentre studies, suggesting the importance of treatment policy, process of care, and/or patient education. ${ }^{14}{ }^{15}$

Impaired performance in critical activities such as driving may occur even with mild hypoglycaemia and in all hypoglycaemic ranges. ${ }^{16}$ Permanent neurophysiological impairment ${ }^{17}$ and delay or impairment of cognitive function in children have been associated with severe hypoglycaemia. ${ }^{18}$ Accidents and premature deaths have been reported, but mainly in older adolescents and adults. ${ }^{19} 20$

Uncertainty after severe hypoglycaemia may lead to worse metabolic control, even when previous metabolic control has been unsatisfactory, and when a cause of the severe hypoglycaemia independent of insulin dosage has been identified. ${ }^{21}$ Severe hypoglycaemia may also cause anxiety, fear, and sleep disturbances in close relatives. ${ }^{22}{ }^{23}$ We previously found severe hypoglycaemia to be associated with lower global quality of life as measured with the EuroQol-5D; it was attributed to differences in the parameters pain/discomfort, anxiety/ depression, and usual activities. ${ }^{24} 25$ Clearly, therefore, considering its total impact, prevention of severe hypoglycaemia needs to be substantially improved. ${ }^{35}$

\section{Prevention of severe hypoglycaemia}

The importance of clear and adequate patient information aimed at treating and preventing hypoglycaemia has been emphasised since the 1920s. ${ }^{2}$ Patient education and active self control are essential in order to prevent severe hypoglycaemia in young people. ${ }^{26} 27$ For example, patients need to be aware of how the risk of severe hypoglycaemia may vary with the season. ${ }^{28}$ Regular snacks between meals may prevent postprandial hypoglycaemia in adults using short or intermediate acting insulin, and have also been advised for a long time in children. ${ }^{92}$ Evening snacks containing slow acting carbohydrates and protein may reduce nocturnal hypoglycaemia. ${ }^{3031}$ Early recognition of symptoms, and early treatment with fast acting glucose are important in preventing mild hypoglycaemia from proceeding into a state of severe hypoglycaemia - that is, when assistance is needed. ${ }^{11}$ Preceding blood glucose control with prophylactic treatment when needed and early treatment when symptoms occur are recommended to prevent cognitive dysfunction and potential accidents in critical task situations such as driving. ${ }^{32}$ There are various strategies for preventing severe hypoglycaemia without compromising metabolic control, with the aim of preventing both acute and long term complications. ${ }^{3}{ }^{13} 27$

Lack of knowledge about various aspects of diabetes treatment has been related to severe hypoglycaemia in adult patients, whereas no association with general educational 
Table 1 Clinical characteristics at baseline for all patients and the three treatment groups, respectively

\begin{tabular}{|c|c|c|c|c|}
\hline & All & Intervention & Controls & Traditionals \\
\hline \multicolumn{5}{|l|}{ Age years } \\
\hline Mean (SD) & $12.6(4.1)$ & $12.7(4.1)$ & $12.5(4.2)$ & 12.7 (3.9) \\
\hline Median (range) & $12.7(2.6-18.9)$ & $13.5(3.7-18.7)$ & $12.7(2.6-18.6)$ & $12.6(4.2-18.9)$ \\
\hline Duration of type 1 diabetes years, mean (SD) & $5.3(3.8)$ & $4.9(3.5)$ & $5.6(4.2)$ & $5.2(3.6)$ \\
\hline Age at onset (years), mean (SD) & $7.3(3.9)$ & $7.4(3.9)$ & $7.0(4.1)$ & $7.7(3.7)$ \\
\hline Boys/girls proportion & 0.83 & 0.84 & 0.81 & 0.84 \\
\hline No. of daily doses, mean (SD) & $5.3(0.9)$ & $5.3(0.8)$ & $5.3(1.0)$ & $5.3(0.9)$ \\
\hline Insulin dose $(\mathrm{U} / \mathrm{kg})$, mean $(\mathrm{SD})$ & $1.0(0.3)$ & $1.0(0.3)$ & $1.0(0.3)$ & $1.0(0.3)$ \\
\hline $\mathrm{HbAlc} \mathrm{c}^{*}(\%)$, mean (SD) & $7.9(1.5)$ & $7.8(1.4)$ & $7.8(1.3)$ & $8.0(1.8)$ \\
\hline Daily BGs, mean $(S D) \dagger$ & $2.5(1.6)$ & $2.7(1.7)$ & $2.4(1.5)$ & $2.6(1.5)$ \\
\hline Direct acting insulin analogue (Lispro or Aspart) (n) & 230 & 73 & 80 & 77 \\
\hline Pump (n) & 21 & 7 & 6 & 8 \\
\hline
\end{tabular}

*National standard Mono-S, on average $1.15 \%$ below DCCT level. ${ }^{34}$

$\dagger B G$, blood glucose tests (self reported average frequency).

level has been found. ${ }^{12}$ As a complement to traditional education methods, development of pedagogical devices and other patient education and information materials is needed. Patients may need information to help them cope, to help others understand their situation, and especially to assist them in self care, so that they can learn how to prevent further illness and complications. ${ }^{33}$

Within a university hospital setting, we previously developed and evaluated for the first time a video and leaflet education material targeted at the prevention of severe hypoglycaemia. ${ }^{13}$ A before and after study design was used; a description of the format and contents of the material has been presented elsewhere. ${ }^{13}$ Our earlier findings supported the hypothesis that improved patient education aimed at the prevention of severe hypoglycaemia may reduce severe hypoglycaemia through various effects on basic knowledge and self treatment behaviours, but controlled studies have been lacking. ${ }^{13}$ We therefore conducted a controlled study in a different patient population.

In the present study we tested the hypothesis that good quality self study material for home use would: (1) be used and disseminated; (2) be perceived as helpful in self treatment; and (3) reduce severe hypoglycaemia without worsening metabolic control as measured by mean HbAlc.

\section{METHODS}

The study base consisted of the 332 type I diabetes children younger than 19 years of age who lived in the catchment areas of the general hospitals in Jönköping, Kalmar, and Västervik. In accordance with the Swedish health care system, all type I diabetes patients aged 1-18 years in these areas were treated at these paediatric clinics. Table 1 presents their clinical characteristics.

The patients and clinics in this study are not those that participated in our previous uncontrolled study, ${ }^{13}$ nor was there any overlap. The intervention material used in the present study consisted of slightly revised versions of the videos evaluated in our earlier study and a novel self study brochure developed and expanded from the leaflets described earlier. ${ }^{13}$

\section{Treatment}

The patients were treated with multiple insulin therapy (97\% $\geqslant 4,82 \% \geqslant 5$ daily doses) combined with active self control, psychosocial support, and education. The selection of insulin and regimens varied, with the aim of meeting the specific needs of the patient. All families received initial training in general management, including recognition and treatment of hypoglycaemia. Quarterly visits were aimed for, but because of limited resources the average number of outpatient visits yearly was $2.2,2.7$, and 2.9 , respectively, in the three clinics.

\section{Protocol}

All the clinically diagnosed type I diabetes children with a duration of diabetes $>0.5$ years at the start of the study in January 2000 were eligible and participated (see fig 1). They and their families were randomised to one of three groups and received:

- Two mailed videotapes and a brochure designed to review skills for self control and treatment, aimed at preventing severe hypoglycaemia (intervention group).

- A mailed videotape and brochure with general diabetes information (controls group).

- Traditional treatment only (traditional group).

\section{Assignment}

Subjects were allocated to the three groups by a third part researcher (SN) using random numbers. Randomisation in 1:1:1 sequence was stratified for clinic, sex, and age. The groups were equal regarding baseline clinical characteristics (table 1).

\section{Masking}

All study participants and personnel were blinded to group assignment for the whole study period as far as possible. The groups received identical presentations of the study and of their information materials, mailed by a third part researcher $(\mathrm{SN})$. Care providers received no information on the specific contents. They were instructed to discuss any clinical issue raised by the patient as usual, without trying to identify the group to which the patient belonged.

\section{Intervention material}

Two video programmes (17 minutes +18 minutes) were mailed in January 2000 to intervention patients. These videos consisted of interview clips of three patients aged 9-14 years and their parents regarding diabetes treatment and the prevention of hypoglycaemia, with sequences from their daily lives, and brief comments from a diabetologist. ${ }^{13}$ The information focused on practical aspects, with a basic optimistic attitude of support towards increasing one's skills in self care.

A novel self study brochure (32 pages, 5200 words), the contents of which were related to that of the video, was mailed one month later. This brochure contained a number of frequently asked questions with answers in discussion form and related suggestions, as in the example given in table 2 . The main contents covered definition and occurrence of severe hypoglycaemia, counter-regulation and warning symptoms, various aspects of prevention in practice, early symptom recognition, and early effective treatment. Separate sections dealt with use and interpretation of 24 hour profiles, urine test strips, random blood glucose, focused blood glucose, and 


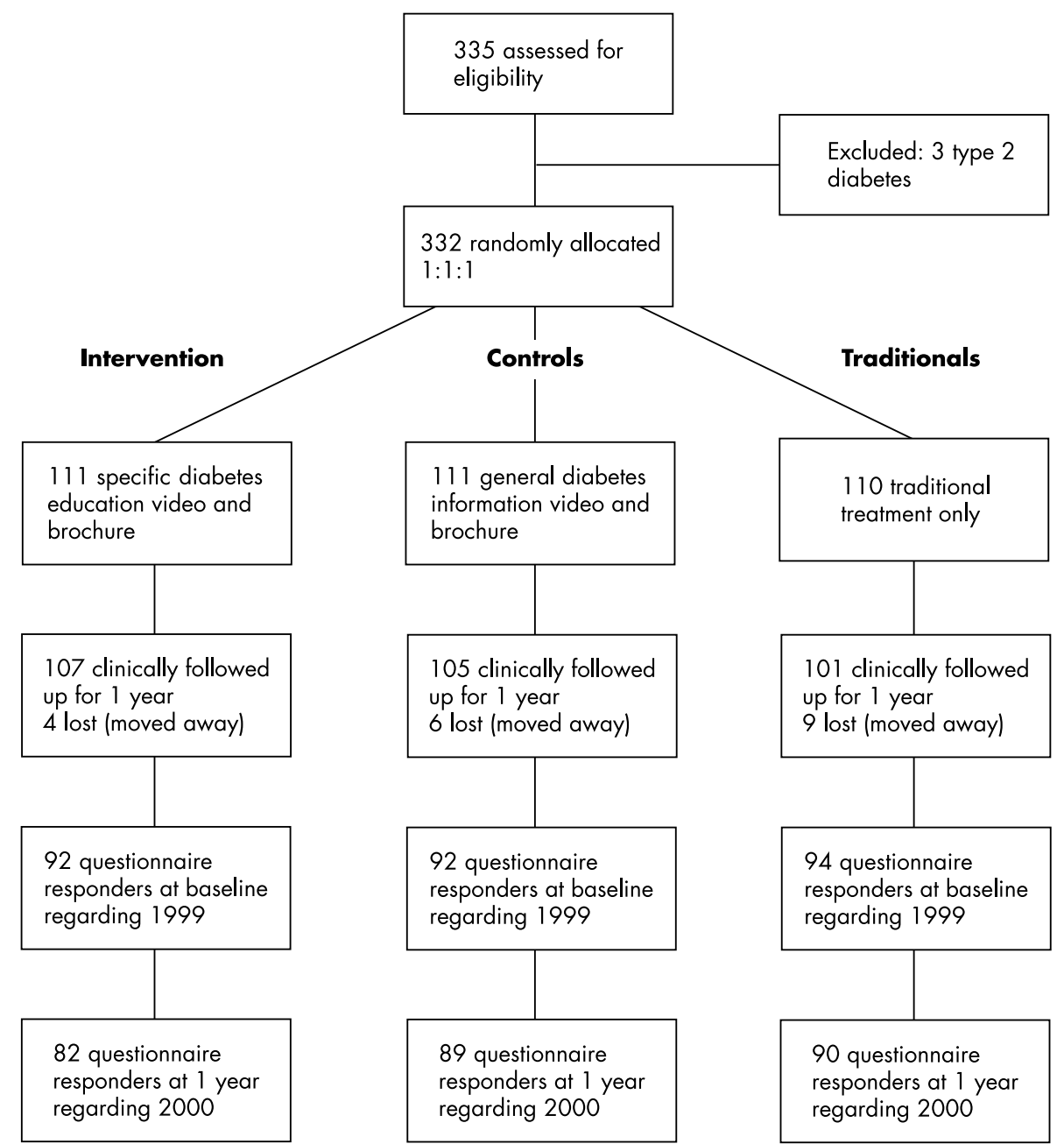

Figure 1 Flow chart of the study. Primary endpoints were $\mathrm{HbAlc}$ determined in clinical follow up, and severe hypoglycaemia determined by means of questionnaires.

HbAlc, aiming at a 24 hour blood glucose as stable and near normal as possible. Implications for particular at risk situations, such as those involving alcohol and those involving traffic were highlighted. A table of key suggestions in the material has been presented earlier. ${ }^{13}$ Other sources of information were also suggested.

As described previously, the material was developed in association with patients and parents, and was based on specific questions raised by them, the best evidence from the literature, relevant guidelines from the International Society for Pediatric and Adolescent Diabetes (ISPAD), and 20 years of clinical experience with intensive treatment by the diabetes team that produced the material. ${ }^{913}$ A group of other medical, psychological, and pedagogical advisors contributed. A psychologist with extensive experience with diabetes families checked the language and content in order to prevent imposing guilt feelings.

\section{Control material}

In January 2000 a videotape (13 minutes) containing general information on type I diabetes for children and families was mailed to controls. It consisted of interview clips regarding

Table 2 Example of question and answer from the intervention brochure

\begin{tabular}{|c|c|c|}
\hline Question & Answer & Suggestion \\
\hline $\begin{array}{l}\text { Can you get serious insulin } \\
\text { reactions from exercise? }\end{array}$ & $\begin{array}{l}\text { Occasional hard exercise or a great } \\
\text { deal of exercise without eating extra } \\
\text { energy/food and without decreasing } \\
\text { your dose of insulin a little can give } \\
\text { you a lower blood sugar during the } \\
\text { time you are exercising, and many } \\
\text { hours after that. You can get a severe } \\
\text { insulin reaction a long time after hard } \\
\text { exercise, and even during the night or } \\
\text { the morning after! }\end{array}$ & $\begin{array}{l}\text { Extra energy is usually needed both before/during exercise as well as } \\
\text { afterwards. The night-time insulin dose often needs to be temporarily decreased } \\
\text { a little after activities like long walks, a disco, sports day, or a football match. } \\
\text { With greatly increased exercise you always have to pay extra attention to your } \\
\text { blood sugar and insulin doses. } \\
\text { This also applies to winter sports holidays/skiing holidays, when sports training } \\
\text { gets underway, and especially when spring comes and you are out and more } \\
\text { active in the evenings. Then it's especially important to do } 24 \text {-hour profiles and } \\
\text { adjust your insulin. One or more doses might need to be decreased during the } \\
\text { spring and early summer. } \\
\text { A new adjustment period comes at the end of the summer and this requires } \\
\text { extra attention. Sometimes certain doses need to be increased. }\end{array}$ \\
\hline
\end{tabular}


Table 3 Incidence of hypoglycaemia

\begin{tabular}{|c|c|c|c|c|c|c|}
\hline \multirow[b]{2}{*}{ Endpoint } & \multicolumn{2}{|c|}{ Intervention group $(n=111)$} & \multicolumn{2}{|c|}{ Control group $(n=111)$} & \multirow{2}{*}{$\begin{array}{l}\text { Difference } \\
\text { unadjusted for } \\
\text { baseline \% } \\
(95 \% \mathrm{Cl})\end{array}$} & \multirow[b]{2}{*}{$p$ value } \\
\hline & 1999 & 2000 & 1999 & 2000 & & \\
\hline \multirow{4}{*}{$\begin{array}{l}\text { Responders } \\
\text { Severe hypoglycaemia, n (\%) } \\
\text { Difference before-after, \% (95\% CI) } \\
\text { p value }\end{array}$} & 92 & 82 & 92 & 89 & & \\
\hline & $38(42)$ & $22(27)$ & $31(34)$ & 33 (37) & $10(-4$ to 24$)$ & NS \\
\hline & \multicolumn{2}{|c|}{$\begin{array}{l}-15(1 \text { to } 29) \\
0.0394\end{array}$} & \multicolumn{2}{|c|}{$+3(-11$ to 17$)$} & & \\
\hline & Median & $\begin{array}{l}25-75 \text { th } \\
\text { centile }\end{array}$ & Median & $\begin{array}{l}25-75 \text { th } \\
\text { centile }\end{array}$ & $\begin{array}{l}\text { Difference } \\
(\mathrm{mm})\end{array}$ & $\mathrm{p}$ value \\
\hline Usefulness of getting video*, VAS (mm) & 53 & $23-72$ & 48 & $25-66$ & & NS \\
\hline Usefulness of getting brochure*, VAS (mm) & 56 & $36-73$ & 46 & $23-59$ & 10 & 0.0283 \\
\hline Learning from videot, VAS (mm) & 48 & $22-68$ & 26 & $9-51$ & 22 & 0.0075 \\
\hline Learning from brochuret, VAS (mm) & 46 & $18-67$ & 27 & $9-50$ & 19 & 0.0049 \\
\hline
\end{tabular}

diabetes with a patient at the age of 10 and then 19 years and his parents, sequences from their daily lives, and brief comments from a diabetologist. A self study brochure containing related material ( 16 pages, 800 words) was mailed one month later. This material projected a basically optimistic attitude towards living a good life with diabetes without discussing in detail any concrete issues of self care.

\section{Access to video players}

Patients receiving videos were informed that a video player was available at the outpatient departments if needed. Based on earlier Swedish population data, it was expected that approximately $95 \%$ of the families would have a video player at home.

\section{Primary outcomes}

The yearly incidence of severe hypoglycaemia was obtained from postal surveys at the start of the study in January 2000 regarding 1999 (baseline), and one year later regarding 2000. These surveys were conducted by the independent Center for Medical Technology Assessment at Linköping University. Patients were informed that individual patient data would not be reported to the diabetes team. The specific question was: "Did you experience episodes of severe hypoglycaemia (needing assistance) during the last 12 months? Yes/No." This was registered without other inclusion or exclusion criteria. Local routine methods for $\mathrm{HbAlc}$ determination, calibrated to the national standard method Mono-S, were utilised..$^{34}$ Since 1997 a national recalibration to the Mono-S standard has resulted in a yearly mean that is on average $1.15 \%$ below the level in the Diabetes Control and Complications Trial (DCCT). ${ }^{34}$

\section{Secondary outcomes}

Patient attitudes and level of use regarding the intervention and control materials, respectively, were evaluated after one year with the postal questionnaire method mentioned above. Open questions combined with visual analogue scales ${ }^{35}$ were mailed to patients under 20 years of age who at this time had had experience with diabetes for at least 18 months.

\section{Analysis}

We used intention to treat analysis for primary outcomes. For statistical analysis, StatView 5.0.1 software (SAS Institute Inc.) was used. As planned, the $\chi^{2}$ test was used for incidence in proportion of patients, and the non-parametric MannWhitney U test for HbAlc and for visual analogue scale readings; $p$ values $\leqslant 0.05$ were regarded as significant. Mean values (1 SD) are given.

\section{Ethics}

The study was approved by the Ethics Committee for Human Research at the Faculty of Health Sciences at Linköping University, Linköping, Sweden.

\section{RESULTS}

A total of 261 of 332 subjects responded to the questionnaire in 2001 (278 at baseline in 2000); 37\% (32\%) were teenagers responding themselves and $37 \%(42 \%)$ answered with some help from their parents. Of the respondents, $97 \%$ had a video player at home.

\section{Severe hypoglycaemia and $\mathrm{HbAlc}$}

After the intervention, the incidence of severe hypoglycaemia during 2000 was reduced in the intervention group from $42 \%$ to $27 \%$ compared with 1999 (risk difference $15 \%, 95 \%$ CI $1 \%$ to $29 \%, p=0.0394)$, but was not reduced in the control and traditional groups. Controls did not differ from traditionals. Table 3 gives absolute figures.

Including only those patients responding both at baseline and after one year, the incidence of severe hypoglycaemia during 2000 was reduced in the intervention group from $45 \%$ to $28 \%$ compared with 1999 (risk difference $17 \%$, 95\% CI 1\% to $32 \%, \mathrm{p}=0.0369$ ).

There were no differences in yearly mean HbAlc levels compared with control and traditional groups or compared with baseline.

\section{Reading and viewing levels}

Twelve months after distribution the intervention brochure had been read in the family a median of two times (range $1-10)$ and the intervention video viewed a median of two times (range 2-10). The control brochure had been read a median of two times (range 1-20) and the control video viewed a median of one time (range 1-20).

Furthermore, $40 \%$ of the intervention subjects ( $43 \%$ of controls) had also shown the brochure to others, mainly relatives, friends, school staff, and sports coaches, and $47 \%$ of intervention subjects ( $49 \%$ of controls) had shown the video to similar persons.

Fifty nine per cent of the intervention subjects ( $51 \%$ of controls) anticipated future use of the brochure, and $60 \%$ of the intervention subjects ( $47 \%$ of controls) anticipated future use of the video.

\section{Perceived benefit}

Within wide ranges, the intervention material was perceived after one year as being of at least some benefit to most patients, as shown in table 3, with higher benefit compared to 
controls from the brochure $(\mathrm{p}=0.0283)$. A greater proportion of intervention subjects than controls indicated that they had learnt something useful from the hypoglycaemia prevention video $(\mathrm{p}=0.0075)$ and the brochure $(\mathrm{p}=0.0049)$.

Intervention subjects with severe hypoglycaemia during 2000 indicated greater benefit from receiving the brochure $(p=0.0126)$ and the video $(p=0.0100)$ than those without severe hypoglycaemia. Moreover, a greater proportion of those with severe hypoglycaemia indicated that they had learnt something useful from the brochure $(p=0.0301)$ and the video $(p=0.0178)$, respectively. No such differences were found in controls.

\section{DISCUSSION}

Ever since it was first used, individuals treated with insulin have needed detailed practical information/education on the prevention of severe hypoglycaemia. ${ }^{2}$ This randomised controlled study shows that the incidence of severe hypoglycaemia (reported as needing assistance by another person) may be reduced with good quality patient education materials.

It also shows that such pedagogical devices may reach high reading, viewing, and dissemination levels at a low cost. This was so even when they were distributed without selection to a geographical population including older adolescents with a long duration of diabetes and those who never experienced severe hypoglycaemia.

The levels of use and perceived benefit of the materials illustrate a general need for good patient/consumer education materials about diseases, treatment options, self care, and prevention of further illness and complications. ${ }^{33}$ Such communication should deal with important issues and risks, with the aim of reducing uncertainty. ${ }^{33}$ To produce good patient information/education materials, collaborative efforts by people with a range of expertise in the fields of medicine, psychology, pedagogy, and the media, and also including patients/consumers in the process, are important. ${ }^{36}$ Careful attention to patient needs and concerns is essential. Patients prefer facilitative, honestly optimistic, structured, and concise information. ${ }^{33}$

\section{The intervention method}

We have discussed the strengths and limitations of this kind of intervention elsewhere. ${ }^{13}$ Distributing a pedagogical device is simple and inexpensive, and dissemination to persons other than close family, which is also important for the child, may occur in many cases. It is easy to show a videotape and then discuss it together.

A combination of pedagogical methods may enhance learning. The combination of a pedagogical device for home use and regular follow up visits offers possibilities for fruitful discussions. ${ }^{13}$ Another option is to view and discuss this material with groups of patients and parents and then to give participants their own copies for home use and further dissemination. Opinions differ on diabetes treatment, and group discussions may stimulate learning.

\section{Strengths and limitations of the study}

With a complete geographical population of this size and a randomised controlled design, an adequate base for studying real world effectiveness is created. Our consistent blinded endpoint registration method in a closed cohort is another strong point. However, at least quarterly prospective registration of severe hypoglycaemia would also be valuable in future studies.

Clinically useful prevention strategies need to minimise severe hypoglycaemia without compromising metabolic control, ${ }^{3927}$ as was done in this study. Using prospective registration and a longer follow up period, it would be worth examining whether this method might contribute to improved self control, reduction of acute complications, and/or a larger knowledge base.

\section{What this paper adds}

\section{What is already known on this subject?}

- Severe hypoglycaemia remains a serious problem in modern insulin treatment

- The risk can probably be reduced with improved education and information, but population studies are lacking

- Patient information materials in general are often incomplete regarding risks and complications

What does this study add?

- This randomised controlled study shows that the major side effect of insulin treatment, severe hypoglycaemia, can be reduced with good quality education materials containing targeted information on the prevention of such acute complications

- Targeted diabetes education that deals with such risks and complications can be perceived as more useful than general diabetes information

- Mass distributed good quality education materials may reach high reading, viewing, and dissemination levels at a low cost

\section{Costs}

As described earlier, the cost for the intervention was estimated at $€ 1000$ per 100 patients. ${ }^{13}$ The yearly socioeconomic cost for severe hypoglycaemia per 100 diabetes patients at a Swedish clinic has been conservatively estimated at $€ 17440$, but costs for possible traffic accidents and other material damage, disablement or premature deaths, effects from worsened control because of uncertainty after events, and consumption of people's leisure time and other intangibles were not included in that figure. ${ }^{25}$

As this method substantially reduced severe hypoglycaemia, the cost for severe hypoglycaemia was correspondingly reduced, resulting in cost savings; the method is therefore cost effective for society. It is also likely to contribute to improved quality of life. ${ }^{25}$

\section{Future approaches to prevention of severe hypoglycaemia}

From a clinical point of view, there is a need for novel approaches to prediction and prevention of severe hypoglycaemia. ${ }^{27}$ The multifactorial aetiology of severe hypoglycaemia offers several possibilities for prevention in the future. ${ }^{5}$ More physiological insulin preparations and regimens, new glucose sensors and alarms, and other improved technologies may contribute to prevention of hypoglycaemia. ${ }^{58}$ Genetic predictors combined with earlier known determinants might prove useful to identify certain patients with a need for more intensive assessment and support (in press). However, intensified education and training in the prevention of severe hypoglycaemia without worsened metabolic control is probably an essential intervention at the present time. ${ }^{527}$

\section{Conclusions}

We found that a pedagogical device for home use that supports diabetes self care and is especially targeted at the prevention of severe hypoglycaemia may contribute to a decrease in severe hypoglycaemia without worsened metabolic control. When mass distributed, such self study materials can be widely disseminated at a low cost. This method may be used as a complement to regular visits to the diabetes team and other types of education.

The level of use and patient preferences suggest that there is a great need for good quality patient/consumer education materials dealing with aspects of general management and risk prevention in diabetes treatment. The findings may also have implications for other topics within diabetes education, other ages, and for other diagnosis groups. 


\section{ACKNOWLEDGEMENTS}

We wish to acknowledge all the participating patients. We thank diabetes nurses Iris Franzén and Eva Isacson, psychologist Marianne Helgesson, Drs Ragnar Hanås, Anders Häger, Johnny Ludvigsson, and Maria Nordwall, TV producer Anders Forslöw, pedagogical consultant Margareta Beerbom-Fallsberg, and health economist Dick Jonsson for valuable viewpoints. The Swedish Child Diabetes Foundation (Barndiabetesfonden), the Health Research Council in the southeast of Sweden (FORSS), the Swedish National Road Administration (Vägverket), and the Center for Medical Technology Assessment (CMT), Dept of Health and Society at Linköping University, supported this study.

\section{Authors' affiliations}

S Nordfeldt, Division of Child and Adolescent Psychiatry, Division of Pediatrics and Center for Medical Technology Assessment, Linköping University, Linköping, Sweden

C Johansson, Department of Paediatrics, Hospital of Jönköping, Sweden E Carlsson, Department of Paediatrics, Hospital of Kalmar, Sweden J-Å Hammersjö, Department of Paediatrics, Hospital of Västervik, Sweden

\section{REFERENCES}

1 Diabetes Control and Complications Trial Research Group. The effect of intensive treatment of diabetes on the development and progression of long-term complications in insulin-dependent diabetes mellitus. N Engl J Med 1993;329:977-86.

2 Joslin E, Gray H, Root H. Insulin in hospital and home. J Metab Res 1922;2:651-99.

3 Cryer PE, Fisher JN, Shamoon H. Hypoglycemia. Diabetes Care 1994; 17:734-55.

4 Diabetes Control and Complications Trial Research Group. Epidemiology of severe hypoglycemia in the diabetes control and complications trial. Am J Med 1991;90:450-9.

5 Nordfeldt S. On severe hypoglycaemia in children and adolescents with type 1 diabetes. Linköping University Medical Dissertations, No. 648. Division of Pediatrics, Faculty of Health Sciences Linköping, Linköping University, 2000; http://www.ep.liu.se/diss/med/06/48/index.html.

6 Åman J, Karlsson I, Wranne L. Symptomatic hypoglycaemia in childhood diabetes: a population-based questionnaire study. Diabet Med 1989;6:257-61

7 Nordfeldt S, Ludvigsson J. Severe hypoglycemia in children with IDDM. A prospective population study, 1992-1994. Diabetes Care 1997;20:497-503

8 Schiaffini R, Ciampalini P, Fierabracci A, et al. The Continuous Glucose Monitoring System (CGMS) in type 1 diabetic children is the way to reduce hypoglycemic risk. Diabetes Metab Res Rev 2002;18:324-9.

9 Nordfeldt S, Ludvigsson J. Adverse events in intensively treated children and adolescents with type 1 diabetes. Acta Paediatr 1999;88:1184-93.

10 Rewers A, Chase HP, Mackenzie T, et al. Predictors of acute complications in children with type 1 diabetes. JAMA 2002;287:251118.

11 Cox DJ, Gonder-Frederick LA, Kovatchev BP, et al. Biopsychobehavioral model of severe hypoglycemia. II. Understanding the risk of severe hypoglycemia. Diabetes Care 1999;22:2018-25

12 Schiel R, Ulbrich S, Muller UA. Quality of diabetes care, diabetes knowledge and risk of severe hypoglycaemia one and four years after participation in a 5-day structured treatment and teaching programme for intensified insulin therapy. Diabetes Metab 1998;24:509-14.

13 Nordfeldt S, Ludvigsson J. Self-study material to prevent severe hypoglycaemia in children and adolescents with type 1 diabetes. A prospective intervention study. Practical Diabetes International 2002;19:131-6.
14 Implementation of treatment protocols in the Diabetes Control and Complications Trial. Diabetes Care 1995;18:361-76.

15 Mortensen HB, Hougaard P. Comparison of metabolic control in a cross-sectional study of 2,873 children and adolescents with IDDM from 18 countries. The Hvidore Study Group on Childhood Diabetes. Diabetes Care 1997;20:714-20

16 Cox DJ, Gonder-Frederick LA, Kovatchev BP, et al. Progressive hypoglycemia's impact on driving simulation performance. Occurrence, awareness and correction. Diabetes Care 2000;23: 163-70.

17 Soltesz G, Acsadi G. Association between diabetes, severe hypoglycaemia, and electroencephalographic abnormalities. Arch Dis Child 1989;64:992-6.

18 Ryan C, Vega A, Drash A. Cognitive deficits in adolescents who developed diabetes early in life. Pediatrics 1985;75:921-7.

19 Sovik O, Thordarson H. Dead-in-bed syndrome in young diabetic patients. Diabetes Care 1999;22(suppl 2):B40-2.

20 Sartor G, Dahlquist G. Short-term mortality in childhood onset insulin-dependent diabetes mellitus: a high frequency of unexpected deaths in bed. Diabet Med 1995;12:607-11.

21 Tupola S, Rajantie J, Akerblom HK. Experience of severe hypoglycaemia may influence both patient's and physician's subsequent treatment policy of insulin-dependent diabetes mellitus. Eur J Pediatr 1998;157:625-7.

22 Pramming S, Thorsteinsson B, Bendtson I, et al. Symptomatic hypoglycaemia in 411 type 1 diabetic patients. Diabet Med 1991;8:217-22.

23 Clarke WL, Gonder-Frederick A, Snyder AL, et al. Maternal fear of hypoglycemia in their children with insulin dependent diabetes mellitus. J Pediatr Endocrinol Metab 1998;11(suppl 1):189-94.

24 The EuroQol Group. EuroQol-a new facility for the measurement of health-related quality of life. Health Policy 1990;16:199-208.

25 Nordfeldt S, Jonsson D. Short-term effects of severe hypoglycaemia in children and adolescents with type 1 diabetes. A cost-of-illness study. Acta Paediatr 2001;90:137-42.

26 Brink SJ. How to apply the experience from the diabetes control and complications trial to children and adolescents? Ann Med 1997:29:425-38.

27 Ludvigsson J, Bolli GB. Intensive insulin treatment in diabetic children. Diabetes Nutr Metab 2001;14:292-304.

28 Nordfeldt S, Ludvigsson J. Seasonal variation of $\mathrm{HbAlc}$ in intensive treatment of children with type 1 diabetes. J Pediatr Endocrinol Metab 2000; 13:529-35

29 Orre-Pettersson AC, Lindstrom T, Bergmark V, et al. The snack is critical for the blood glucose profile during treatment with regular insulin preprandially. J Intern Med 1999;245:41-5

30 Detlofson I, Kroon M, Åman J. Oral bedtime cornstarch supplementation reduces the risk for nocturnal hypoglycaemia in young children with type 1 diabetes. Acta Paediatr 1999;88:595-7.

31 Winiger G, Keller U, Laager R, et al. Protein content of the evening meal and nocturnal plasma glucose regulation in type-l diabetic subjects. Horm Res 1995;44:101-4.

32 Weinger K, Kinsley BT, Levy CJ, et al. The perception of safe driving ability during hypoglycemia in patients with type 1 diabetes mellitus. Am I Med 1999:107:246-53.

33 Coulter A, Entwistle V, Gilbert D. Sharing decisions with patients: is the information good enough? BM 1999;318:318-22.

34 Arnqvist H, Wallensteen M, Jeppson JO. [Standards for long-term measures of blood sugar are established]. Lakartidningen 1997;94:4789-90

35 McCormack HM, Horne DJ, Sheather S. Clinical applications of visual analogue scales: a critical review. Psychol Med 1988;18:1007-19.

36 Entwistle VA, Watt IS, Davis $\mathrm{H}$, et al. Developing information materials to present the findings of technology assessments to consumers. The experience of the NHS Centre for Reviews and Dissemination. Int J Technol Assess Health Care 1998;14:47-70. 